\title{
ALTERIDADES GEOPOLIITICAS Y CONSTRUCCIÓN DE CONOCIMIENTO EN LAS FRONTERAS DE LA MODERNIDAD
}

\section{FRANCISCO TIAPA*}

Este ensayo deriva de un conjunto de investigaciones inscritas en las agendas de la antropología social e histórica de las fronteras del Sistema Mundo. En un primer momento, esta agenda fue el marco de una serie de trabajos sobre la historia de los procesos de reinvención cultural y política de las poblaciones indígenas del Oriente de Venezuela durante la época colonial (Tiapa, 2007a, 2007b, 2007c, 2007d, 2008a, 2008b, 2008c, 2010, 2013a, 2014a). En estos trabajos, fue constante la conexión entre conocimiento, cultura y poder, en el marco de los proyectos coloniales y de diagramación de un nuevo orden de coacción social, a lo largo de los siglos XVII y XVIII. A esto se han seguido otras investigaciones, de corte etnográfico, entre poblaciones indígenas Mako (Hohotï), del río Ventuari en la Amazonía venezolana, entre los Kari'ña de la Mesa de Guanipa (Tiapa, 2012, 2014b) y sobre las poblaciones campesinas de los Andes venezolanos ${ }^{1}$ (Tiapa, 2013b). En estas experiencias, la relación entre diferentes universos culturales dio cuenta de que la imagen sobre el "conocimiento" no necesariamente estaba directamente vinculada con su dimensión funcional. Por el contrario, en los contextos de intersección cultural, hablar sobre conocimiento implicaba hacer alusión a categorías de status y de legitimación de las posiciones de ejercicio de poder ${ }^{2}$.
En el marco de la Antropología Histórica del colonialismo, los testimonios históricos reflejaban la imagen que los misioneros tenían sobre una auto-atribuida diferencia jerárquica entre sus estilos de vida y los de aquellos indígenas que se pretendían evangelizar. Esto estuvo presente en diferentes momentos de la historia de la expansión de las fronteras coloniales sobre las poblaciones de filiación lingüística Caribe de la costa oriental de Venezuela y del río Orinoco. Al representar los estilos de vida de las poblaciones indígenas que se oponían a la imposición cultural, los autores de los testimonios fueron recurrentes en hacer alusión a las formas en que estas sociedades se relacionaban con su entorno, sus sistemas económicos, sus regímenes políticos y sobre sus pautas de movilidad territorial. Junto a estas esferas de sus vidas colectivas, también se hizo alusión a la manera en que estas poblaciones construían "conocimiento". Es decir, los testimonios en sí ubicaban en cierto sistema de jerarquías a las costumbres de los otros, de modo que se les evaluaba, en términos de una representación valorativa, a fin de justificar las razones para la imposición de la cultura colonial.

La jerarquización de la cultura de "los otros" dio cuenta de un juego de representaciones donde la imagen sobre aquello que estos "sabían

\footnotetext{
* Profesor Agregado, Departamento de Antropología y Sociología, Universidad de los Andes, Mérida, Venezuela. Correo-e: francisco.tiapa@gmail.com
} 
hacer" era una idea continuamente presente. En tal sentido, a lo largo del trabajo de sistematización y análisis de estas fuentes, surgió la duda sobre el uso político del conocimiento, que aun cuando no se le llamaba de esa manera, sí estuvo presente, a veces fantasmalmente, como una forma de capital simbólico (Bourdieu, 2008) en la dinámica de relaciones de poder entre los sujetos pertenecientes a estos contrastantes universos de significación de la realidad. Esto indujo una primera preocupación por las geopolíticas del conocimiento que influenció las orientaciones de las siguientes investigaciones.

En el marco de los trabajos etnográficos entre los Mako del río Ventuari, de los Kari'ña del Orinoco y de las poblaciones campesinas de los Andes, el problema del conocimiento fue transversal a los diferentes ámbitos de las relaciones entre los agentes locales, a lo interno de sus espacios sociales, así como entre ellos y los agentes foráneos. En esta segunda esfera de articulación entre sujetos, la "legitimidad" de los saberes fue un tópico central, también como forma de construcción de capitales simbólicos que incidían en las relaciones de poder alrededor de las imágenes sobre la tierra y el entorno ambiental, en el marco de las relaciones entre poblaciones indígenas y Estado, así como entre poblaciones campesinas y comerciantes agrícolas urbanos. Aun cuando estos trabajos, inicialmente, estuvieron guiados por las plataformas teóricas de la Antropología Ecológica, el problema de la relación entre conocimiento y poder volvió a ser patente.

A partir de este marco de experiencias, en este espacio se presenta un nuevo avance en torno a las reflexiones derivadas de la preocupación por formular una agenda teórica y de investigación sobre los constreñimientos coloniales y post-co- loniales en la producción de conocimiento. Aunque el referente empírico que lo motiva se deriva de las realidades pasadas y presentes de poblaciones geográficamente circunscritas a regiones fronterizas del orden global, la orientación se dirige a la comprensión de realidades culturales y políticas más amplias. De hecho, se pone de lado la idea de que las investigaciones antropológicas se restringen a límites espaciales concretos y que los debates derivados de ella solamente pueden hacer alusión a tal delimitación, para incluir discusiones generales sobre las realidades concretas de la producción del pensamiento social. Tales realidades pueden abarcar a los entornos sociales inmediatos de los académicos, a sus marcos institucionales o a procesos históricos en amplios espectros temporales. En tal sentido, a lo largo de este texto, la alusión a historias globales está acompañada de referencias a experiencias en marcos vivenciales heterogéneos, donde el lugar de enunciación del observador se convierte en objeto de estudio. Paradójicamente, tal transgresión a las rigurosidades más básicas de cualquier producción intelectual, al mismo tiempo se adhiere a lo establecido por el principio general de que, para el punto de vista de un antropólogo, todo fenómeno estudiado debe ser visto como un "acto social total" (Lévi-Strauss, 1991), al límite de que se visibilice el marco de construcción subjetiva del analista.

El fin de este ensayo es elaborar una crítica sobre el nivel supra-histórico de las relaciones entre colonialismo y conocimiento. En tal sentido, a lo largo del texto se harán generalizaciones asociadas con realidades pasadas al mismo tiempo que contemporáneas, a fin de dar cuenta de las continuidades del eurocentrismo, más allá de sus contingencias históricas. El argumento central gira en torno a la idea de 
que, aunque contextos tan heterogéneos como el contacto colonial entre los siglos XVI y XVIII $y$ las actuales relaciones entre poblaciones indígenas y criollas, son situaciones empíricamente diferentes, éstas han sido envueltas por un marco discursivo común, vigente en nuestros propios espacios institucionales.

Esta reflexión estará guiada por cuatro vectores. En primer lugar, se abordará la base mítica de la imagen de la Verdad Universal, como el sustrato de conexión entre eurocentrismo, conocimiento y conciencia geopolítica. En segundo lugar, se discutirá la contradicción entre auto-atribución de racionalidad y acción irracional colonial, desde la idea de Modernidad como forma de construcción de alteridad y de identidad patrimonial. En tercer lugar, se hará una asociación entre la figura del Sujeto Moderno y la configuración de imágenes ubicuas de jerarquías geopolíticas en las fronteras del orden global. Finalmente, se hará una aproximación a las relaciones entre producción de conocimiento y proyectos civilizatorios en las fronteras de la Modernidad. Intencionalmente, se busca establecer asociaciones teóricas extensibles a contextos disímiles, pues se parte del principio de que el parcelamiento de realidades de análisis es en sí mismo un recurso que impide ver las dimensiones globales e irreflexivas del colonialismo. Más que tratarse de un análisis sobre las tensiones y contradicciones en torno a la construcción de conocimiento en espacios fronterizos, este trabajo se orienta a elaborar un marco crítico desde esos espacios hacia la cultura de referencia del analista, pues se parte del principio de que ésta es en sí el marco general de la supresión de las diversidades culturales a lo largo del globo. Por lo tanto, se recalca que nuestro compromiso ético no puede restringirse únicamente a la visibilización de esas diferencias, sino al cuestionamiento de nuestros propios espacios de producción intelectual.

\section{Verdad Universal y naturalización del lugar de enunciación colonial}

La asociación entre colonialismo y conocimiento deriva de la ubicuidad global y del alcance meta-histórico de la idea de la Verdad Universal como recurso discursivo de naturalización del eurocentrismo. En las historias fronterizas, es posible observar la irradiación multi-espacial y macro-histórica de la irracionalidad de la Modernidad, a partir de su uso como recurso para la imposición de proyectos civilizatorios sobre aquellas sociedades sometidas por el colonialismo. Tal irradiación no se restringe a tiempos y espacios lejanos, sino que se encuentra vigente dentro de nuestros propios entornos de producción intelectual. La recurrencia de estas conexiones entre conocimiento y poder deriva de una mirada colonial sobre el mundo, bajo la cual subyace un modelo epistemológico desplegado por la Modernidad occidental (Castro-Gómez, 2007). Esta irradiación deriva de la configuración de un patrón de pensamiento que parte del principio de que una sola visión de mundo, a partir de un único lugar de enunciación, es capaz de elaborar representaciones de la realidad susceptibles de ser proyectadas hacia múltiples ámbitos globales. Desde esta plataforma inobservada de observación epistemológicamente unificada, la mirada eurocéntrica representada por le ciencia moderna "...pretende ubicarse en el punto cero de observación para ser como Dios, pero no logra observar como Dios" (CastroGómez, 2007, p. 83). A lo largo de la expan- 
sión del Sistema Mundo Moderno (Wallerstein, 1976), la idea de la Verdad Universal ha sido la dimensión discursiva de la mundialización del patrón cultural colonial por medio de la fuerza (Dussel, 2000). En tal sentido, la acción concreta de la imposición colonial a lo largo del globo es constitutiva de la creación del mito de su universalidad. Tal idea de la verdad, forma parte del armazón perceptivo de lo que cada cultura, en este caso la cultura colonial y neocoIonial, considera como conocimiento. La idea de conocimiento alude al ámbito de una cultura en la que se producen los enunciados generales que marcan el lindero entre lo verdadero y lo falso, entre lo correcto y lo errado, entre lo que se debe seguir y lo que se debe desechar. El conocimiento, como cuerpo de representaciones, cubre la totalidad de los ámbitos de existencia de una sociedad. En función de este conjunto de representaciones, se definen las formas de delinear los perfiles personales, las relaciones con el medio ambiente, las prácticas alimentarias, la curación de las enfermedades, las decisiones colectivas, las trayectorias de vidas individuales, etc. El conocimiento está imbricado con la representación cultural en general, pero dentro de ella ocupa un lugar especial. Según los enunciados emitidos desde la esfera del conocimiento, se establecen principios de autoridad y de obediencia, pues se trata de una forma de ver la realidad cuya connotación cobra un carácter sagrado, aun cuando se trate de un ámbito secular de la existencia. En tal sentido, sobre la base de la posesión de conocimiento se establecen las jerarquías del cuerpo social, pues el conocimiento define la imagen de la Verdad 3 .

Una representación puede ser considerada cultural cuando es irreflexiva e incuestionable, pues se encuentra inmersa en un entramado ubicuo de significaciones, que se sigue sin saber por qué, o bien que se sabe, pero sin que se sepa cuándo o por qué llegó a saberse. De hecho, la cultura en sí misma es opaca, en el sentido que le dio Geertz (1996) a esta categoría. Por su parte, el conocimiento puede ser entendido en los mismos términos en que Foucault (1979a) definió a la episteme, como el ámbito en que los sujetos de una cultura en particular buscan observar a su propio marco irreflexivo desde fuera. Tal intención de encontrar, o inventar, un lugar de percepción capaz de ver desde fuera a la propia cultura puede derivar en la deconstrucción de las bases irreflexivas del universo discursivo del observador. Sin embargo, esta posición también puede derivar en una condición de existencia dirigida a la reafirmación de las propias bases irreflexivas que en cierto momento se buscó deconstruir y en relación con las cuales se quiso buscar respuestas. Ahora bien, entre la representación irreflexiva y la reafirmativa existen diferencias. Ciertamente ambas tienen contenidos similares pues se sustentan sobre formas de ordenamiento de la realidad configuradas históricamente de forma inconsciente. Más allá de este denominador común, la diferencia está en que el pensamiento irreflexivo configura enunciados sobre la realidad de forma fragmentaria, sustentados en un lenguaje silencioso, ausentes de argumentos sostenidos y adheridos a la idea de "lo obvio", como aquello que no puede ser argumentado, pues se dice que es de cierta manera "solo porque sí". Por su parte, la reafirmación de la realidad, se sustenta sobre argumentos basados en reflexiones conscientes, se ilustra por medio de evidencias, se re-crea por medio de procedimientos y es capaz de trascender la idea de lo obvio, a pesar de que su fin último sea fortalecer la obviedad. 
La reafirmación del orden irreflexivamente establecido deriva en el pensamiento dogmático, como principio rector de los diferentes órdenes culturales ${ }^{4}$. En la dinámica de tensiones y contradicciones del Sistema Mundo Moderno, tal caracterización del saber, como construcción cultural, se mezcla con el hecho concreto de que los centros hegemónicos del globo también son los centros de producción de conocimiento (Wallerstein, 1996). Más allá de una mayor complejidad y solidez en cuanto a los saberes producidos en estos centros geopolíticos, su autoridad se nutre de la capacidad económica, política y militar de imponer y dominar al resto de los pueblos del mundo. Siguiendo el argumento de Edward Said (1990), tal derivación no es sencillamente un resultado unidireccional, sino que las "verdades" construidas desde estos centros reafirman y velan el hecho concreto de la dominación imperial. Al estar sustentadas sobre la idea de que hay una linealidad temporal de avance indetenible e irreversible que sigue un mismo recorrido y en el que Europa se encuentra en la cúspide, estas formaciones discursivas de reafirmación sustentan el principio de que la única forma de estar a la par del ideal de sociedad es tener como modelo de imitación a los países dominantes dentro de este rango civilizatorio (Wolf, 1987).

Como parte de una serie de ramificaciones derivadas de este discurso de dominación, hay otras ideas esencializadas y constitutivas del mito de la superioridad cultural, como la racial, la de género, la de clase, la tecnológica, el discurso sobre el desarrollo, la depredación sobre el medio ambiente, el mito del progreso, etc. De este modo, las tensiones geoculturales se reproducen en otros ámbitos, como las relaciones de clase o de género, con la misma dinámica de dependencia mutua e intereses contradictorios. Desde este patrón de representación, estas tensiones, contradicciones y fricciones entre clases sociales, grupos culturales y de orientación sexual son presentadas y explicadas como una suerte de fases de transición por las que todos los pueblos del mundo deben pasar para poder homologarse con quienes se considera que son representativos del máximo estadio de la evolución humana.

El sustrato que justifica esta teleología presentada como el sentido común de la transformación social, se basa en la supuesta tendencia de todas las culturas a la búsqueda de un mayor sentido de la explotación de la mano de obra de los sectores sociales ubicados en las escalas más bajas de sus jerarquías, así como de un mayor "provecho" del medio ambiente. De esta manera, se naturaliza el principio de que habría una sola Historia o Evolución, negándose cualquier posibilidad de que las transformaciones de las diversas poblaciones del mundo se encuentren vinculadas con las diversas formas de articulación entre sus visiones de mundo, sus tensiones políticas y las posibilidades y limitaciones de los diversos ecosistemas que habitan, en relación con el conocimiento que se tenga sobre éstos.

En esta dinámica histórico-cultural, la producción de conocimiento tiene un valor relativo según el lugar de enunciación discursiva, definida por el posicionamiento geopolítico de la verdad. El lugar de enunciación define diferentes visiones de mundo, variables según la posición relativa desde dónde éste se construye. Este "dónde" tiene jerarquías diferenciales. A partir del "lugar de enunciación" (Mignolo, 2001) configurado desde los espacios de producción de conocimiento del Atlántico Norte -como una subjetividad geopolítica unificada- se han elaborado 
modos de discursos, construidos para relacionarse con los pueblos que históricamente han sido subyugados por medio de la expansión colonial y neocolonial. Tales modos discursivos se basan en los lugares especiales que éstos han ocupado en la propia experiencia de la así llamada Europa "occidental".

Una de las principales estrategias de naturalización de esta construcción de conciencia colonizadora es el intento de separar el conocimiento político del así llamado conocimiento "puro". La plataforma de tal ficción es el consenso de que el conocimiento "verdadero" es fundamentalmente no político y que el conocimiento abiertamente político no es verdadero. Esto oculta las "condiciones políticas oscuras" y muy bien organizadas que rigen cualquier producción de saber. Asimismo, se ocultan los condicionantes reales y geopolíticamente marcados de la construcción subjetiva de una realidad dada. Por el contrario, una obra humanística, o una noticia en los medios de comunicación, no puede permanecer ajena a las implicaciones que su autor tiene en tanto sujeto humano, determinado por las circunstancias de su propia realidad. Este sujeto se enfrenta al resto de las sociedades del mundo o a los grupos sociales y culturales de su propio entorno, primero según su adscripción geo-cultural y después como individuo (Said, 1990). Tal forma de conciencia puede ser reproducida por aquellos que no necesariamente pertenezcan a esta clasificación geopolítica. En tal sentido, lo que Occidente (como representación) y aquellos que se identifican a sí mismos bajo la categoría ambigua de occidentales dicen sobre otras sociedades no es una realidad en sí, sino un juego de representaciones, imbuidas de relaciones imperiales que definen la conciencia de los sujetos que las configuran.
Para los discursos del colonialismo, el eje principal de la construcción de la propia identidad y de la diferencia sobre otras sociedades se solapa sobre el ordenamiento espacial, a lo largo del planeta, de supuestas diferencias jerárquicas basadas en la presencia o ausencia del logro del ideal de la riqueza y la tecnología. Tal construcción tiene sus principales exponentes en el interior del mundo académico, pero es más evidente en las esferas mediáticas, donde una y otra vez, se resalta esta supuesta diferencia entre los pueblos que se perciben a sí mismos como "civilizados" y aquellos que se consideran "atrasados".

En este marco discursivo, la imagen de la Verdad Universal da cuenta de la raíz mítica e irracional de la idea de Modernidad como construcción de alteridad. Por medio de la reafirmación de esta imagen, fue posible la proyección de las legitimaciones de las relaciones coloniales de poder, de modo que fuesen capaces de trascender sus constreñimientos territoriales originarios y sus contingencias históricas. En sus bases culturales, esta se funda sobre el amplio conjunto de representaciones míticas que sostienen a la religión cristiana. En su dimensión secular, este principio se trasladó al pensamiento moderno por medio de la idea de que los enunciados derivados del pensamiento científico, al igual que las verdades de la religión cristiana en el pasado, tendrían validez por encima de cualquier representación generada en otro marco cultural que no fuese aquello que, en el contexto de las relaciones coloniales, genérica y ambiguamente se ha considerado como "lo europeo". En su raíz religiosa, la idea de la "Verdad Universal" fue la recreación de la imagen de la deidad omnipresente, omnisciente y omnipotente. A partir de este sustrato 
irreflexivo, la cultura colonial se estableció sobre la asociación entre su capacidad global de irradiación (omnipresencia), su posibilidad de imposición (omnipotencia) y la idea de que, por asociación lógica, su visión de mundo no podía sino ser la correcta mientras que las otras estaban equivocadas (omnisciencia). En el siguiente segmento, se abordará la reflexión en torno a este patrón de pensamiento, no en su sustantividad, sino en su configuración como forma de construcción de identidad y alteridad en medio de los contrastes geopolíticamente jerarquizados.

\section{La Modernidad como construcción colonial de alteridad}

Dentro del marco cultural de las sociedades europeas y criollas transatlánticas, las historias del pensamiento científico social y filosófico de los últimos dos siglos han hecho un esfuerzo generalizado por caracterizar la propia época, en contraste con otras épocas que se piensan superadas. Ejemplos como el de Augusto Comte (1965 [1845]) muestran cómo el surgimiento mismo de la teoría social se basó en la construcción de un relato mito-histórico que buscó establecer una diferencia entre una época "científica" y otra "religiosa" o "metafísica". Algo similar ocurrió con el proyecto intelectual marxista, dirigido a la relativización de su propia especificidad histórica, al llamarla "Capitalismo", como una fase a ser superada en pro de la construcción del futuro comunista, dentro del marco de la sociedad industrial (Marx \& Engels, 1979 [1859]). En el presente, el consenso generalizado del pensamiento social se dirige a caracterizar la época en que se vive como "Modernidad", también percibida como una fase en el tiempo que, de manera teleoló- gica, eventualmente pasará o que ya pasó, para abrir las puertas a la así llamada post-modernidad (Lyotard, 1987). De una manera u otra, las esferas de conocimiento de la autodenominada cultura occidental han buscado relativizarse a sí mismas, por medio de la objetivación de su propia visión de mundo, a veces con la intención de refirmarla y en ocasiones con la intención de deconstruirla. Para los fines de la presente reflexión, es posible tomar la categoría de Modernidad a fin de hacer alusión al patrón cultural vigente en el mundo contemporáneo, desde los inicios de la mundialización del cristianismo, del conocimiento científico y del capitalismo por medio del colonialismo. Si bien estas categorías hacen alusión a esquemas perceptivos y a prácticas colectivas que, desde una mirada intracultural, se ven como mutuamente excluyentes, el argumento presente es que no hay linderos claros entre ellas y que se trata de diferentes formas de construcción de identidad, por contraste con las imágenes ambiguas y genéricas proyectadas sobre otras poblaciones a lo largo del planeta.

En tal sentido, la así llamada Modernidad históricamente se ha configurado como una narrativa de construcción de identidad por contraste con otras formas de representación de la realidad. En este marco perceptivo, los territorios y espacios sociales que han enmarcado a los encuentros interculturales han sido los contextos de interacción conflictiva entre modos de vida tan divergentes que, a su vez, se han constituido como los referentes fundacionales de esta forma de auto-percepción. Dado que toda construcción de identidad es constitutiva de la proyección de la alteridad (Tiapa, 2011), la imagen sobre "los otros" coloniales se ha establecido como el referente negativo para la configuración de la idea de 
Modernidad como forma de auto-reafirmación del sujeto colonizador. Esta doble imagen del "nosotros moderno" y la de "los otros" pensados como "no-modernos" ha estado acompañada de relaciones violentas, dirigidas a la supresión física y a la objetivación de los pueblos colonizados. Tal objetivación ha tenido en su sustrato fines económicos, pero en su expresión externa ha trascendido históricamente por medio de la elaboración de un cuerpo de conocimientos de legitimación del derecho a la colonización, sobre la base de la imagen de la autoatribuida superioridad intelectual de los pueblos colonizadores. En tal sentido, la mundialización del colonialismo por medio de la fuerza se ha naturalizado y se ha reproducido históricamente a partir de su universalización discursiva, es decir, a través de la abstracción del conjunto de representaciones configuradas en los espacios de encuentro colonial (Dussel, 2000).

En este contexto de argumentación, es posible afirmar que en el transcurso de la configuración del Sistema Mundo (Wallerstein, 1976), el referente imaginario de la Modernidad no es un patrón de pensamiento con cualidades intelectuales diferentes a las de cualquier otro esquema perceptivo míticamente sustentado. Su sentido de distinción no está basado en capacidades funcionales superiores, sino que es una forma de construcción de identidad contrastante (Caroso de Oliveira, 1992) que en su sustancia se ha nutrido, en ciertos momentos, de contenidos correspondientes con el así llamado "pensamiento científico", pero que mayoritariamente ha estado atravesado de narrativas míticas internamente contradictorias. Además de ser una forma de contraste, la retórica de "lo moderno" ha sido una forma de construcción de identidad patrimonial; es decir, se piensa singular no por sus características intrínsecas, sino solo porque se percibe como "lo propio". En tal sentido, el así llamado pensamiento "Moderno" surge como un recurso simbólico de diferenciación en el marco de las relaciones sociales verticalizadas de los contextos coloniales y neocoloniales

En las fronteras del Sistema Mundo, este recurso de diferenciación se visibiliza por medio de la contradicción entre la imagen de la racionalidad europea y las acciones que, desde esta misma clasificación, podrían ser consideradas como irracionales. Esto puede ser ilustrado por medio de las referencias a los contextos de contacto colonial y neo-colonial en las fronteras caribeñas y amazónicas desde el siglo XVI hasta el presente. Por ejemplo, en la costa oriental del Caribe, en el transcurso del siglo $\mathrm{XVI}$, las relaciones entre conjuntos culturales mostraron la contradicción entre las lógicas de sociabilidad basadas en acuerdos de reciprocidad, por parte de las poblaciones indígenas, y la tendencia al descontrol y a la constante ruptura de tratos de no agresión, por parte de los europeos. Tales rupturas derivaban de la incomprensión de las lógicas de articulación entre espacios indígenas cohesionados entre sí. Mientras se hacía un trato con un asentamiento, se atacaba otro que se pensaba desconectado, lo que daba como resultado la organización de rebeliones en regiones extensas, con alcances geográficos que trascendían los límites perceptivos de los primeros colonizadores. El resultado fue que, esta región, a pesar de ser la primera en tratar de ser conquistada, fue la última en ser parcialmente controlada, a finales del siglo XVIII (Tiapa, 2004, 2007a, 2008a). Así, durante este período histórico, esta violencia en el nombre de la civilidad se evidenció por medio de proyectos misionales que mostraron cómo 
-en el nombre de tal ideal de superioridad cultural- las políticas de reducción de poblaciones indígenas se hacían por medios represivos, sin correspondencia con la imagen de la racionalidad según la cual se proyectaba la vida en las misiones. Las "entradas" armadas y los castigos ejemplares dirigidos a crear ambientes de terror dieron cuenta de esta contradicción complementaria entre violencia y razón (AGI, Santo Domingo, 582: 15-12-1699).

La irracionalidad moderno-colonial llegó a su momento de naturalización por medio de la contradicción entre la idealización de los espacios sociales y las posibilidades y limitaciones ambientales de la región. Las misiones y los asentamientos hispanos y criollos fueron asociados con la mitificación de los poblados metropolitanos, sobre la base de retóricas de urbanidad como formas de representación identitaria patrimonial. Por contraste, los asentamientos indígenas fueron vistos como pequeñas unidades dispersas, cuando se trataba de redes de asentamientos articuladas en extensos territorios, de una manera tal que cada unidad tenía unas dimensiones correspondientes con las capacidades de carga de sus contextos ambientales. En tal sentido, la incapacidad de los españoles para comprender los medios ambientes tropicales derivó en la dependencia por el conocimiento ecológico indígena, al mismo tiempo que tal dependencia fue constantemente negada. Esto se evidenció por medio de los fallidos proyectos urbanos en las regiones áridas, como Píritu, donde las grandes concentraciones poblacionales no estuvieron acordes con la escasez de agua (Tiapa, 2007d). De igual manera, en regiones húmedas, como en el Golfo de Paria, los contextos ecológicos no coincidían con los parámetros europeos del paisaje cultural ideal, por ser considerados "lugares enfermos" (AGI, Santo Domingo, 642: 16-08-1712). Aún más, después de casi tres siglos de presencia en las regiones tropicales, la adherencia identitaria a los paisajes templados tuvo como resultado la continuidad de proyectos de modificación ecológica que aún para la década de 1780 mostraban ser fallidos (AGN, Traslados, Cumaná, Tomo. XI. Doc. 1: folios 1-39; Tomo. XVII, folios 238-389; XIX; Doc. 1; folios 5-43).

Esta contradicción entre racionalidad moderna -como identidad patrimonial- e irracionalidad fronteriza también se ha exteriorizado por medio de las relaciones entre Estado y poblaciones indígenas en la Amazonía contemporánea. En esta región, los proyectos civilizatorios sobre las poblaciones indígenas se han sustentado sobre el principio de la reafirmación compulsiva de los referentes culturales modernos y la negación de la capacidad funcional de los sistemas adaptativos indígenas. En el río Ventuari, hacia finales del siglo $\mathrm{XX}$, las acciones gubernamentales en el nombre del progreso tuvieron como realización práctica a los planes de construcción de viviendas para poblaciones indígenas en áreas que, desde el punto de vista de los criollos, se consideraban "prístinas". Las viviendas construidas durante las décadas de 1980 y 1990 tenían características infraestructurales que no encajaban con las condiciones ambientales de la región. Las casas eran de techos de zinc y bajos, poco ventiladas y de espacios pequeños. Sin embargo, en la retórica oficial y en los posteriores textos históricos distribuidos en los espacios educativos venezolanos, se consideró que este había sido un avance, en contraste con las viviendas indígenas de bahareque y techos de paja, donde se albergaban los vectores de transmisión del Mal de Chagas. 
Si bien no se trata de desmeritar la posible relación entre las estructuras indígenas y el vector de esta enfermedad, es importante señalar que la planificación de estas viviendas fue unidireccional y que, de haberse hecho en diálogo con el conocimiento indígena, los resultados hubiesen sido diferentes. Así, en el presente, es común ver cómo en las poblaciones amazónicas, estas casas no son más que depósitos de materiales para la navegación fluvial o la agricultura, sin ningún valor habitacional. En vez de ser tratadas como logros de la civilización, estos espacios son una añadidura instrumental. De hecho, detrás de cada casa construida por los criollos, hay una vivienda de bahareque y techo de paja, donde corre el aire fresco y donde se realizan las actividades correspondientes con el habitar o con la cohesión cotidiana. Desde un punto de vista eurocéntrico, esta fusión de técnicas arquitectónicas sería percibida como una negación irracional a la civilización. Sin embargo, de ser así, ni habría uso instrumental de la imposición infraestructural del Estado, ni habría fusión de técnicas arquitectónicas. De hecho, otros recursos preventivos de las enfermedades, como el uso de los mosquiteros o los hábitos de limpieza, son efectivamente usados por los indígenas Mako, aun cuando se trate de hábitos dependientes de manufacturas o insumos tecnológicos recientemente adquiridos.

Estos ejemplos ilustran cómo, en los espacios fronterizos, la auto-atribuida imagen de racionalidad del pensamiento moderno establece parámetros de humanidad contradictorios con sus realizaciones prácticas. Es precisamente en estos lugares donde el pensamiento moderno se funda, pues éste se hace por contraste con la diferencia y no por una caracterización positiva de sí mismo. Tal contradicción no se expresa en la adherencia a pautas de comportamiento consideradas como más civilizadas o por su capacidad para responder a las vicisitudes sociales o ambientales de los escenarios sobre los cuales se impone la así llamada Modernidad. Por el contrario, estas pautas adquieren un valor patrimonial, al tratarse de recursos identitarios cuya condición de positividad reside en su sentido de pertenencia. Desde este punto de vista, las otras sociedades serían percibidas como irracionales solo por ser diferentes, aun cuando posean pautas de socialización o de adaptación ambiental cuyos resultados demuestren una mayor funcionalidad por medio del equilibrio con su entorno humano o no humano. Esta aprehensión a lo que se piensa como lo propio puede llegar al punto del fracaso del proyecto civilizatorio mismo, incluso cuando este sea compulsivamente deseado y violentamente impuesto por el sujeto colonizador. Tal sujeto tiene la capacidad de imponerse gracias a su condición de anonimato, pues no se muestra como aquel cuya presencia deriva del proyecto colonizador en sí, sino que lo hace a partir de la imagen del así llamado Sujeto Moderno, la cual será abordada en la siguiente sección.

\section{Frontera colonial y Sujeto Moderno}

En los contextos fronterizos, se visibilizan formas de construcción de alteridad que en los espacios metropolitanos contemporáneos se encuentran velados por medio de los recursos retóricos irreflexivos del colonialismo. Tales recursos se sustentan en la imagen ambigua y espectral del Sujeto Moderno, como imposición ontológica sobre otras formas de pensar la noción de persona. A fin de hacer una proyección desde las fronteras hacia los centros (Sahlins, 1997), es necesario abordar la manera 
en que esta imagen se irradia a lo largo del orden global. En las sociedades culturalmente mestizas del continente americano, las minorías que se han percibido a sí mismas como descendientes de las distintas oleadas migratorias que se han sucedido desde el siglo XVI, han convivido y se han mezclado tanto con los grupos sociales descendientes tanto de los pueblos nativos, como de los pueblos secuestrados desde el continente africano (Mignolo, 2000). En su proceso de estructuración -en el sentido de Giddens (1996)- la verticalidad social latinoamericana estableció una idea de grupos elitescos percibidos a sí mismos como la homologación de los representantes de los centros hegemónicos globales. En su existencia, estos grupos dominantes han hecho el intento de asemejarse a una imagen espectral de lo que creen que es el deber ser de la "civilidad", sustentada en un conjunto de símbolos, genéricos e internamente contradictorios, de la europeidad.

En estos contextos fronterizos, se ha establecido históricamente el referente imaginario que guiaría el sentido común del Sistema Mundo. De este modo, la experiencia histórica latinoamericana fue el contexto de la coexistencia entre la experiencia concreta mezcla y la idea de la necesidad de distinción interracial. Esto hizo que la América Hispano-Lusitana fuese el primer contexto donde el referente simbólico de la Modernidad surgiese como forma de construcción de alteridad, pues al haber mayor convivencia con "los otros" del sujeto colonizador, fue más urgente la búsqueda de imágenes de distanciamiento entre colonizadores y colonizados. Posteriormente, las experiencias coloniales de África y Asia, con sus propias singularidades, se sustentarían sobre este primer modelo simbólico. Al tener sus propias especificidades, estos nuevos procesos de choques culturales reenviarían a América Latina nuevos discursos, como parte de una dinámica multidireccional de símbolos colonizadores. Sobre las relaciones concretas de los ámbitos geográficos circunscritos, históricamente se ensambló una imagen globalmente ubicua que se trasladó indiferentemente hacia los tres continentes sujetos al control colonial (Dussel, 2000). Eventualmente, estos orígenes geográficos de los imaginarios coloniales se perdieron de vista, de modo que se llegó a estructurar un esquema generalizado globalmente extendido sobre el deber ser de las relaciones entre el auto-atribuido sujeto moderno y los pueblos considerados como pre-modernos.

En los contextos neocoloniales, como los Estados Nacionales latinoamericanos, la imagen naturalizada y mitificada de los descendientes culturales de los europeos se ha impuesto como modelo de referencia, bien sea porque quienes se atribuyan su posesión tengan o no una coherencia con la forma de lo que se percibe como lo "europeo"; o bien sea que estos tengan un aspecto o que reproduzcan costumbres que en relación con "otros", los hagan más "europeos". Así, se ha creado la proyección espectral de los "descendientes" culturales de los europeos definidos así solo por el contraste con otros que se piensa que no lo son. Los ejemplos de grupos mestizos y hasta indígenas amazónicos, percibidos a sí mismos como "más civilizados" que otros que se cree que no lo son, muestran como la europeidad se ha convertido en un recurso identitario que ha sido usado según las relaciones de poder inscritas en diferentes contingencias históricas (Tiapa, 2005, 20065 , 2011, notas de campo).

Sobre la configuración de las culturas criollas latinoamericanas, se ha sustentado el referente 
simbólico de la subjetividad colonial y eurocéntrica a lo largo del Sistema Mundo. Tal referente, hallegado a ser el marco paradigmático de definición de la Modernidad, como forma de construcción de identidad incluso en los contextos considerados como "centros" del sistema global. Esta hipótesis de trabajo se inserta en la postura de que la historia de la Modernidad requiere una perspectiva que vaya más allá de las narrativas que ubican a este marco discursivo en Inglaterra, Alemania y Francia, de modo que trasladan a una posición explicativamente periférica a las experiencias coloniales hispanoamericanas, entre los siglos XVI y XVIII (Dussel, 2000), las cuales antecedieron práctica y retóricamente a las historias locales europeas. En el marco de los proyectos civilizatorios latinoamericanos, se vivió la experiencia del control de la mezcla entre diferentes grupos culturales. Por lo tanto, América Latina fue el primer escenario de elaboración de retóricas, de carácter extra-provinciano, dirigidas al establecimiento de un lindero identitario entre lo moderno y lo "no moderno", es decir, entre lo "blanco" y lo "no blanco". A partir de esta afirmación, es meritorio tomar en consideración la idea de que los procesos coloniales hispanoamericanos fundaron las bases de la "Primera Modernidad" (Dussel, 2000; Mignolo, 2000). Dado que la configuración de las culturas criollas fue una de las principales singularidades sustantivas de estas primeras experiencias históricas, resulta sugerente la idea de que la Modernidad, como modelo cultural subsumido al cristianismo, surgió precisamente en estos marcos culturales, más que en los espacios institucionales metropolitanos.

Dentro de los procesos socioculturales de mezcla e hibridación, la distinción entre colonizador y colonizado se diluyó en un amplio gradiente de interacciones y representaciones, donde una heterogeneidad aún hoy indiscernible de sincretismos contrastó con un conjunto restringido de categorías clasificatorias, impuestas como formas de construcción de identidad, a partir del referente hegemónico de la imagen del "blanco", "civilizado" o "moderno", como modelo de imitación. Siguiendo a Mignolo (2000), esto derivó en una contradicción entre imaginario y estructuración, en la cual, la dinámica multicultural de las sociedades criollas se vio solapada por la idea de que ser criollo ha sido históricamente el sinónimo de ser no solo "moderno" o "blanco", sino "europeo". Así, las diferentes formas de auto-percepción criolla forman parte de un conjunto de conciencias dobles (Mignolo, 2000) que viven la contradicción entre una estructuración mestiza y un imaginario que se percibe a sí mismo como "blanco". De esta manera, las identidades criollas representan el sustrato fundacional de las subjetividades coloniales, al tratarse de formas de representación sustentadas en la ambigüedad de auto-percibirse como algo que no consideran que sean del todo.

En el Oriente de Venezuela, durante la época colonial, la contradicción entre auto-percepción y realización práctica de las representaciones coloniales también se evidenció por medio de la configuración fronteriza de la imagen de la criollidad. Por ejemplo, hacia el siglo XVIII, la figura jurídica de "español" fue atribuida a espacios sociales considerados así no por estar poblados por españoles o por sus descendientes directos, sino por el contraste con las poblaciones indígenas (Abad [1773] 1974). En ciertos casos, los criollos de frontera llegaron a crear un continuo con las poblaciones indígenas por medio de la configuración de redes familiares multi-étnicas (AGI, Santo Domingo, 642: 16-08-1712). Sin embargo, en momentos 
contingentes, la acción de las agencias colonizadoras llevó a que los criollos no-blancos se percibiesen a sí mismos como "blancos" a tal punto en que llegaron a ser los ejecutores de las acciones violentas para la represión de las poblaciones nativas que se negaban a insertarse en los espacios de coerción colonial (AGI, Santo Domingo, 644 [31-05-1752], 1968).

En el río Ventuari, a lo largo del siglo $\mathrm{XX}$, la acción violenta de los criollos, en el nombre de la identidad colonizadora, llegó a tal punto que cobró una dimensión supra-local y ubicua que trascendió los linderos de su acción práctica directa. Entre los Mako, las referencias a su propia historia e incluso a sus representaciones identitarias estuvieron asociadas con los relatos sobre la violencia ejercida por los criollos. Estos relatos se encuentran cargados de descripciones de asesinatos masivos, esclavizaciones y violaciones de habitantes de comunidades enteras. En función de estos testimonios, los Mako explican sus actuales pautas de asentamiento y de movilidad, además de que construyen su propio contraste con una figura ubicua con la que establecen una relación ambigua entre negación y necesidad de imitación. Así, hacia finales del siglo XX, la ubicuidad de la figura del criollo, como forma de traslado de la idea de la europeidad a contextos culturales fronterizos, llegó al punto en que la colonización del río Ventuari no se dio por parte de los criollos en sí, sino por medio de los indígenas Piaroa (Uwothujja) que, por oposición con los Mako, eran considerados más criollos. En este proceso, el uso de la idea de conocimiento como capital simbólico de dominación se dio por medio de los oficios que, en el esquema neocolonial, se consideraban útiles. Los Piaroa -a pesar de enfrentar sus propias relaciones de subordinación y contradicción con los criollos en las fronteras de los espacios urbanos- en el río Ventuari ocuparon cargos de maestros, enfermeros, comisarios y capitanes. Su posición jerárquica en la región se sustentó en la idea de que éstos poseían un "conocimiento" que les permitía acceder a los recursos materiales y simbólicos provenientes de las ciudades. En los contextos cotidianos de interacción, éste conocimiento -que no necesitaba ser demostrado- llegó al punto en que los Piaroa establecieron relaciones de verticalidad y de cohesión interna similares a las que establecería un colonizador europeo con otros contextos indígenas. En las primeras dos décadas del siglo XXI, esta figura del indígena criollizado comenzó a pugnar con los Kurripako migrantes desde los ríos Guaviare e Inírida, de Colombia, quienes además maximizaron su posesión de conocimiento sobre el universo cultural criollo al comunicarse con los Mako solo en español. En un contexto multilingüe, donde la comunicación entre indígenas no necesariamente es en español, el uso de este código tiene más que un valor funcional, pues se trata de una marca de distinción y de aproximación a la criollidad.

Así, al fundarse como recurso de identidad contrastante (Cardoso de Oliveira, 1992), el conocimiento Moderno no se define por su caracterización positiva, sino por su oposición con un juego de alteridades que, aunque están en constante cambio, tienen como referente fijo a la figura del Sujeto Moderno. Tal figura se proyecta como una imagen ambigua cuyo status reside en recursos que no necesariamente tienen un valor funcional, sino por su asociación indirecta con una imagen racista que en el contexto global tiene una forma precisa, pero que en las fronteras tiene una forma difusa. A partir de esta forma espacial e históricamente contingente, se configura una retórica 
donde los otros negativamente representados se asimilan a un sujeto de referencia, positivamente proyectado hacia lo que se piensa que debería ser el futuro. De este modo, el contraste con la diferencia es la base para la configuración de proyectos civilizatorios, donde el otro o bien es domesticado, por medio de un proceso previo de supresión o de asimilación cultural, o bien es exterminado.

\section{Modernidad, conocimiento y proyectos civilizatorios}

Desde las primeras conquistas territoriales iniciadas en el siglo XVI, la sustancia de la hegemonía eurocéntrica se formó de manera constitutiva con la subjetividad fundante de lo que luego sería el pensamiento científico, basado en el ego cogito cartesiano, pues éste "...fue antecedido en más de un siglo por el ego conquiro (Yo conquisto) práctico del hispano-lusitano que impuso su voluntad (la primera Voluntad-de-poder moderna) al indio americano" (Dussel, 2000, p. 48). Tal dominación sustantiva, al reforzar el mito de la superioridad cultural europea, puso su énfasis sobre la hegemonía capitalista a lo interno de este universo de representaciones. Sin embargo, en la experiencia histórica latinoamericana no fue posible la reproducción exacta del paisaje humano ideal para la cultura dominante, pues la amalgama cultural que integra a esta región derivó en una heterogeneidad social ajena a las capacidades de comprensión por parte de los sujetos reproductores del discurso colonial y neo-colonial. En contextos como estos, la forma de colonización ha tenido que echar mano de los proyectos civilizatorios de homogeneización y supresión cultural (en el sentido de Bonfil
Batalla, 1989). Así, las relaciones de poder en el Sistema Mundo Moderno en términos políticos y económicos al ser constitutivas de la dominación cultural, se traducen en la construcción de supuestas "verdades" sobre lo que se piensa que es el mundo. De este modo, lo que en el pasado fue la verdad de la Iglesia, en el presente es la "verdad" de lo que políticamente se impone como conocimiento científico (Lander, 2000a, 2000b). Ambas imágenes de la verdad entran en la misma teleología judeocristiana que reproduce la lógica del recorrido bíblico, del Génesis al Apocalipsis, en las teorías evolucionistas y que tiene su correlato práctico en las teorías económicas sobre el desarrollo y el progreso (Fabian, 1983). Esta dominación cultural, entonces, necesita de la producción de un conocimiento legitimado por instancias institucionales de coerción simbólica, para validarse, reproducirse en el tiempo y extenderse en el espacio.

La posibilidad de que estos discursos de poder (Foucault, 1981) se hayan proyectado más allá de sus límites espaciales y temporales se encuentra estrechamente vinculada con la elaboración de meta-narrativas con tendencia a naturalizar la imagen del crecimiento centrífugo de la Modernidad hacia otras regiones del mundo. Según estas teorías reproductoras del esquema euro-centrado de explicación del origen del orden global, el sistema capitalista y por lo tanto la Modernidad (como su dimensión narrativa), se generó históricamente en los centros geopolíticos globales $\mathrm{y}$, desde allí, se trasladó hacia las periferias. Esta postura es compartida por líneas de pensamiento tan contradictorias entre sí como las teorías weberianas y las marxistas. Así, para Weber (2001), el capitalismo se configuró como derivación de un ethos protestante, como una 
dimensión intrínseca a los pueblos europeos y, desde allí, comenzó su irradiación global. Por su parte, la aplicación marxista a la historia de las conexiones globales se plasmó en la obra de Lenin (1975 [1917]), para quien la expansión imperial solo fue posible luego de que los grandes monopolios controlaran el panorama económico y político de Europa durante la Revolución Industrial.

Ahora bien, si nos ubicamos geopolíticamente en un lugar que tome en cuenta los procesos históricos que resultaron de la colonización de América a partir del siglo XVI, nos encontramos con un panorama un tanto diferente. En lugar de imaginar a la construcción de las así llamadas periferias desde los centros, históricamente ha sido evidente que son las regiones fronterizas las que han configurado a los centros hegemónicos (Coronil, 2002). La generación de riqueza en las colonias españolas sirvió como fuente para la acumulación de capital en el resto de Europa, más allá de los límites de España. Sobre la base de esta "acumulación originaria" trasatlántica, los países europeos, con sus diferencias internas, pero con una misma identidad geo-cultural, pudieron solidificarse y contraponerse a los reinos musulmanes del Sur del Mediterráneo, lo que conllevó progresivamente a un posicionamiento hegemónico de los primeros y a su ulterior expansión por el resto del mundo (Dussel, 2000). Este proceso de consolidación de la hegemonía global de Europa tuvo fases diferentes, en las cuales los centros hegemónicos intraeuropeos fueron cambiando al mismo tiempo que cambiaron sus frentes de expansión y la atención sobre nuevas regiones fronterizas por conquistar (Wolf, 1987 Wallerstein, 1976; Mignolo, 2001). Entre los siglos XVI y XVIII, se pasó de América al Extremo Oriente, lo que a su vez permitió la posterior dominación del Medio Oriente, de la India y de África (Wolf, 1987. Así, la consolidación en nuevas fronteras fue cambiando el panorama en el resto de las áreas geopolíticas, con lo que se configuró lo que hoy conocemos como el Sistema Mundo Moderno/Colonial (Mignolo, 2000). A lo largo de la configuración de este sistema, se ha creado un conjunto de conciencias geopolíticas (Said, 1990) independientes de las ubicaciones geográficas y de los contenidos culturales cotidianamente exteriorizados. Sea que se trate de grupos históricamente descendientes de europeos o no, la posición geográfica fuera de Europa no es una barrera para la reproducción de esta conciencia geopolítica de continuación de la hegemonía de la llamada sociedad occidental frente a sus vecinos a los que se ha percibido como menos parecidos a este modelo social de referencia (Mignolo, 2001).

Esta dinámica global de configuración de los imaginarios de la Modernidad se encuentra atravesada por juegos de relaciones de poder a partir de la configuración de la imagen del sujeto civilizado como modelo de referencia. Puesto que tal imagen se forma mediante contrastes con otras invenciones ambiguas sobre "los otros", al mismo tiempo que se encuentra nutrida de discursos míticos de auto-reafirmación, la dominación relacional ha sido constitutiva de una dominación sustantiva, de contenidos que definen el modelo de vida y la distribución diferencial de jerarquías entre sujetos sociales. De manera constitutiva con la elaboración imaginaria del sujeto ideal, se encuentra la naturalización e irradiación ubicua de las imágenes de la espacialidad, como recipiente de la civilidad (Pagden, 1988). En esta irradiación, se han axiomatizado los referentes organizativos del Estado Nación Moderno, como naturalización de la condición colonial y como sustrato 
lógico para la proyección sobre las alteridades en el tiempo y en el espacio. Al ser una imagen ubicua, el esquema esencialista de la territorialidad del Estado Nación se ha proyecto sobre otras sociedades incluso cuando se trata de esgrimir un argumento o una acción que se presenta como una forma de reivindicación de la diferencia.

Un ejemplo, entre otros, está en el caso de los proyectos de demarcación de tierras y hábitats indígenas. El proceso de la reafirmación de las titulaciones de tierras indígenas es efectivamente una urgencia y posiblemente la única forma de legitimación frente a la expansión de las grandes corporaciones, los grupos ganaderos y las agencias del Estado. Sin embargo, la auto-demarcación actual está planteada según los esquemas espaciales del Estado Nación Moderno; es decir, a partir del modelo de la homologación entre etnia, cultura y territorio. En contextos de oposición dicotómica indígena-no indígena tales títulos efectivamente se corresponden con las perspectivas territoriales locales. Ahora bien, en las regiones amazónicas, esta lógica dista de ser equivalente a las extensiones territoriales donde el modelo colonial y neo-colonial ha sido incapaz de imponerse. En estas regiones, los territorios multiétnicos se han configurado a partir un sentido identitario basado en el conocimiento ambiental y no en la posesión exclusiva de espacios circunscritos. Por ejemplo, los Mako son gente de la selva (=Tebo Hohotï) y los Kurripako son gente de río, pero no por poseer estos espacios sobre los cuales se ejerce la propiedad, sino por poseer un conocimiento particular que les permite accionar sobre ellos. A esto se añade que no se concibe que la presencia de otra etnia en su territorio sea motivo de conflicto o de búsqueda de purezas correlativas con el territorio.
Al comenzar el proceso de demarcación en los términos del pensamiento Moderno, tal sentido de la tolerancia a la diferencia se ha llegado a ver en una situación de discontinuidad y hasta de potencial conflicto. En suma, la naturalización del pensamiento moderno llegó a tal punto que incluso en los planes estatales, dirigidos a la reivindicación de las poblaciones indígenas, se estaba imponiendo un nuevo proyecto civilizatorio. Una vez más, el proyecto de la Modernidad requeriría del reconocimiento de la condición subjetiva de otras visiones de mundo y el otorgamiento del status epistemológico de otras formas de construcción de conocimiento.

Sobre la base de una historia fronteriza como esta, es posible a observar desde fuera al conocimiento moderno como aquel generado en los espacios dominantes del Sistema Mundo y que, al obviar u ocultar las conexiones entre presente y pasado o entre frontera e institución de conocimiento, se ha convertido en una de las principales agencias de imposición de la condición irreflexiva del eurocentrismo y del racismo. La posibilidad de identificar formas de construcción de alteridad basadas en la construcción de conocimiento en contextos tan divergentes invita a una reflexión orientada a la proyección hacia espacios y tiempos más amplios. Una reflexión como esta no puede circunscribirse a los territorios indígenas, sino también a la cultura de referencia del analista y a su conexión con los imaginarios globales. Al abordar a los proyectos civilizatorios del pasado -como la costa Caribe del siglo XVI- o de regiones lejanas a nuestros universos culturales de referencia -como el Norte de la Amazonía- se corre el riesgo de atribuirles una posición de lejanía y por lo tanto desvincularlos de nuestras pautas naturalizadas de representación de la realidad. El peligro de tal desconexión reside en la poten- 
cial tendencia a reafirmación de los discursos de dominación por medio de la negación de su continuidad y de su irradiación incluso por quienes niegan identificarse con ellos. En tal sentido, vale la pena retomar los argumentos críticos en torno a la globalidad de las bases epistemológicas del eurocentrismo, no solo a fin de poder comprender por qué se reproducen en realidades tan diferentes, sino a fin de denunciar su presencia en nuestros propios espacios institucionales.

\section{Conclusión: Conocimiento moderno y totalización de la diferencia}

La idea de Modernidad surgió históricamente como una retórica de construcción de identidad colonizadora en las fronteras del Sistema Mundo Moderno. Tal imagen fue originalmente reproducida e instrumentalizada por la así llamada "cultura criolla", inicialmente en el contexto latinoamericano y luego irradiada en el resto del orden global. Como su referente sustantivo, se ha creado un cuerpo de conocimientos orientados a legitimar y a naturalizar las condiciones de verticalidad entre el así llamado pensamiento moderno y el resto de los sistemas culturales coaccionados por los órdenes coloniales y neo-coloniales. En esta dinámica, la cultura criolla ha exteriorizado la representación de la auto-atribución de europeidad, al ser un conjunto de esferas sociales que viven la contradicción entre su referente empírico mestizo y su imaginario auto-atribuidamente "moderno", "civilizado", "europeo" o "blanco". Con la naturalización de las meta-narrativas de la Modernidad -en el sentido que le dio Lyotard a esta categoría (1987, 1999)-, como la única forma de pensar la Historia, se han creado discursos en un nivel más consciente desde los cuales se ha argumentado la necesidad de los acuerdos de libre comercio, las intervenciones diplomáticas, los bombardeos y las invasiones. De este modo, los discursos del colonialismo -no solo como un modo de producción, sino como unformación discursiva (Foucault, 1979a, 1979b) diagramadora de la realidad- vendrían a ser los principales juegos retóricos orientados a la totalización de las diversidades culturales a lo largo del Sistema Mundo. Tal totalización tiene que ver con la invención de la idea de Occidente como una abstracción geocultural representada incluso en contextos sociales que no necesariamente coinciden con su imagen dominante. Esta imagen, a su vez, está orientada por la necesidad de homogeneizar, en términos políticos y económicos, a las sociedades que han pretendido subyugar a lo largo de los cinco siglos de colonialismo. Así, los ideólogos del eurocentrismo, han tenido la principal responsabilidad de crear y difundir este discurso de adiestramiento simbólico de la diversidad cultural. Más que ser parte de un pasado colonial e imperial que, según ellos, ya no existe, esto hoy tiene mayor vigencia que nunca, debido a su alta sofisticación y a las distintas vías de transmisión que emplea (Lander, 2000). De este modo, el Sistema Mundo Moderno nace con la expansión colonial de Europa, pero se estructura a partir de la distribución diferencial de poder entre los centros y las periferias (Wallerstein, 1976). Aun cuando en los últimos cinco siglos este sistema ha fluctuado en cuanto a la distribución de estos centros de poder, también ha mantenido en su sustancia la reafirmación de la supuesta superioridad de una cultura europea genérica sobre el resto de las culturas del mundo. Este discurso de la superioridad cultural se ha sustentado históricamente tanto 
en la posibilidad de imponerse por la fuerza como por la configuración de imaginarios sobre la sociedad ideal (Gruzinski, 1994).

La reflexión en torno a la producción de conocimiento desde y sobre las esferas culturales configuradas fuera de los linderos del patrón de pensamiento moderno implica una reconfiguración de las categorías y paradigmas de análisis que han guiado a los principios generales por medio de los cuales históricamente hemos entendido a la realidad. Esto deriva en una revisión de los macroprocesos históricos que han enmarcado a la creación y la naturalización de los supuestos básicos subyacentes (Gouldner, 1979) que, desde los puntos de vista globalmente hegemónicos, han ordenado y diagramado a la realidad con la que nos confrontamos cotidianamente. Esta revisión conlleva un proceso de transformación profunda de nuestras bases discursivas sobre la sociedad global, de un modo tal que se hace prioritaria la comprensión de la dinámica de relaciones de poder y de los juegos de construcción de identidad en las que nos encontramos imbuidos como sujetos productores de conocimiento. Este marco de imágenes y discursos que potencian y al mismo tiempo constriñen a las representaciones conceptuales sobre la sociedad en general es el de las tensiones y contradicciones entre el colonialismo -como sistema estructurado de relaciones globales de poder- y la amplia gama de pueblos del Sistema Mundo Moderno que han buscado distintas vías para responder a este macro sistema de dominación.

A lo largo de la época colonial, en la cuenca del río Orinoco, el contacto entre europeos e indígenas estuvo atravesado por diferentes formas de construcción del saber, asociadas con las dinámicas de representación de la diferencia étnica y ambiental. Esta transversalidad fue abordada a partir de la contradicción entre la auto-atribución europea de racionalidad y la irracionalidad de sus acciones concretas en los contextos fronterizos, derivada del uso del conocimiento como forma de construcción de identidad patrimonial. Esta contradicción entre proyección de la imagen de racionalidad y las acciones irracionales del colonialismo no se restringen únicamente a la violencia, sino a la incapacidad de comprensión de las diferencias culturales en los espacios fronterizos del sistema global. Tal discordancia en contextos tan divergentes se explica con el uso del conocimiento moderno como recurso arbitrariamente configurado para la construcción de identidad patrimonial del eurocentrismo. Dada su constante mutabilidad y contradicción interna, es posible afirmar que la Modernidad es una forma de identificación "...que como proceso actúa a través de la diferencia, [que] entraña un trabajo discursivo, [por medio de] la marcación y ratificación de límites simbólicos, [para la] la producción de efectos de frontera" (Hall, 2003, p. 16). Esta forma de construcción de identidad por contraste se ha presentado, en el marco del pensamiento intra-europeo, por medio de la proyección de los referentes imaginarios sobre otras culturas hacia los que se imagina como el pasado europeo. Así, a partir del recurso de la temporalización del espacio, se ha configurado una imagen abstracta donde el pasado remoto y empíricamente inaccesible de la propia Europa, se construye a partir de la imagen ambigua sobre las culturas que han coexistido con las sociedades coloniales a lo largo del globo (Fabian, 1983).

Frente a la supra-historicidad y la globalidad del pensamiento moderno, es necesario visibi- 
lizar no solo a las formas de su imposición inconsciente o de su irradiación ubicua, sino al lugar del Sujeto de producción de conocimiento dentro de este proceso. En tal sentido, la aún remota posibilidad de des-ensamblaje de las retóricas del colonialismo pasa por la puesta en evidencia del lugar de enunciación desde donde se construyen los parámetros de la Verdad. No se trata de des-montar al pensamiento moderno o a las formas de producción científica en el nombre de una anti-modernidad dogmática y basada en los esquemas míticos de las religiones mediterráneas. Ya esta experiencia histórica es bien conocida y los resultados de la imposición del fascismo, el dogmatismo y el oscurantismo son también conocidos. Se trata de deslastrar al conocimiento moderno de sus bases dogmáticas y pre-científicas sustentadas en principios identitarios eurocéntricos. Tales principios tienen una dimensión ubicua donde las alteridades geopolíticas son cambiantes y difusas. Ante a la europeidad, la identidad criolla es considerada de menor escala, como una copia de mala calidad de lo que se piensa que es el ideal de persona y de cultura. Al mismo tiempo, desde la criollidad, esta imagen se proyecta sobre las sociedades indígenas, las cuales establecen sus propias formas de sujeción y dominación a partir de la irradiación fronteriza de las retóricas de la Modernidad. Al estar basadas en el recurso simbólico del conocimiento, estas retóricas adquieren un carácter sagrado y difícil de ser cuestionado. Ahora bien, desde las experiencias históricas pasadas y contemporáneas de resistencia indígena, es posible ver cómo la condición de exterioridad en relación con el ideal de la Modernidad es un lugar privilegiado para una nueva forma de racionalidad susceptible de ser definida en positivo. Efectivamente, al tratarse de una manera de resistir a un macro-sistema de dominación global, la resistencia también se hace por contraste. Sin embargo, al ser formas de racionalidad dirigidas a la inclusión de la subalternidad dentro de un sistema hegemónico, necesariamente la Modernidad también se ha configurado en función del diálogo con la diferencia. En otras palabras, a fin de aproximarnos al ideal de la razón, antes que nada, es necesario des-centrar el sentido patrimonial e identitario que los imaginarios racistas, eurocéntricos y patriarcales han sido capitalizado como La Verdad Universal, para mostrarla no como la única verdad, sino como una versión de la verdad entre una amplia heterogeneidad de posibilidades distribuidas a lo largo de las fronteras del Sistema Mundo. 


\section{Notas}

1 Datos aún no publicados sobre investigaciones de campo realizadas entre los Mako (Hohotï) del río Ventuari $(2005,2006$, 2011), poblaciones campesinas de Mérida $(2007,2008,2009)$ y los Kari'ña de la Mesa de Guanipa $(2008,2011,2012)$.

${ }^{2}$ Agradezco la lectura y comentarios de Argelia RodríguezContreras, Alejandro Ochoa y José Efraín Contreras, así como de los aportes de los árbitros anónimos. En todo caso, las ideas expuestas son de mi responsabilidad.

${ }^{3}$ El uso de mayúscula para hacer alusión a la "Verdad" en este espacio deriva de su connotación como recurso identitario y de imposición de poder en contextos fronterizos de una manera tal que su connotación diluye su significado inicial hasta hacer que éste se pierda de perspectiva.

${ }^{4}$ El empleo indistinto entre conocimiento en general y conocimiento

\section{Referencias bibliográficas}

Abad, I. [1773] (1974). Viaje a la América. Título Original: Viage a la Provincia de Cumaná, Descripción de todos sus pueblos y relación de su estado y consistencia en el año de 1773. Madrid: Banco de Ahorro y Préstamo.

Archivo General de la Nación, Caracas. Sección Traslados, Colección Cumaná.Testimonios de la Visitas Públicas y Pesquisas Secretas del oidor Real, Luis de Chávez y Mendoza a los pueblos de Nuestra Señora del Amparo de Pozuelo, Tomo XI, folios 1-39; Nuestra Señora de la Concepción de Píritu, Tomo. XVII, folios 238-389; y San Bernardino de Guerteguar, Tomo XIX, folios 5-43.

Archivo General de Indias, Sevilla, Sección Santo Domingo, Legajo 582. Documentos relativos al proceso contra el alzamiento indígena en la Misión de Arenas en la Isla de Trinidad. Del 15 de diciembre de 1699 a enero de 1700). 116 folios.

Archivo General de Indias, Sevilla. Sección Santo Domingo, Legajo 642. Informe de fray Pablo de Godojos al Consejo de Indias, en el que describe el traslado de los habitantes de la misión de Santa Isabel de Paria a la misión de San Francisco de Chacaracuar e incluye los padrones generales de ambos pueblos. 16 de agosto de 1712. 42 folios.

Archivo General de Indias, Sección Santo Domingo, Legajo 644. Acuerdo de los religiosos capuchinos de la misión de Cumaná, Fray Antonio de Catalayud, Fray Antonio de Belchite y Fray Miguel de Vivel, sobre la restitución a los mismos de los pueblos por ellos fundados en la mencionada provincia y que estaban al cuidado de los sacerdotes seculares. Santa María de los Ángeles, 31 de mayo de 1752. En Carrocera, Buenaventura (1968): Misión de los Capuchinos en Cumaná. Tomo III. Caracas, Academia Nacional de la Historia, p.p. 173-194.

Bonfil Batalla, G. (1989). La teoría del control cultural en el estudio de los procesos étnicos. Arinsana, 10, 5-36. científico en particular tiene que ver precisamente con su uso como recurso identitario en contextos fronterizos, donde éste se vacía de contenido y tiene más un valor relacional que funcional.

${ }^{5}$ Estas referencias se encuentran en notas de trabajos de campo aún no publicados, realizados en el río Ventuari, del Estado Amazonas, de Venezuela, en los años 2005, 2006 y 2011. En estos trabajos de campo, fue posible ver cómo la idea de civilidad estuvo directamente vinculada con la adscripción a una imagen ubicua que, a su vez, fue el referente de distinción entre poblaciones criollas y poblaciones indígenas e incluso entre diferentes poblaciones indígenas, incluso en aquellos casos en que tal recurso identitario no estuviese conscientemente dirigido a insertarse en la imagen que globalmente se asume como moderna.

Bourdieu, P. (2008). El sentido práctico. Barcelona: Siglo XXI.

Cardoso de Oliveira, R. (1992). Etnicidad y estructura social. México D.F: CIESAS.

Carrocera, B. (1968). Misión de los Capuchinos en Cumaná. Caracas: Academia Nacional de la Historia.

Castro-Gómez, S. (2007). Decolonizar la universidad. La hybris del punto cero y el diálogo de saberes. En Castro-Gómez, S. \& Grosfuguel, R. (Eds.), El giro decolonial. Reflexiones para una diversidad epistémica más allá del capitalismo global. Bogotá: Siglo del Hombre Editores.

Comte, A. [1845] (1965). Discurso sobre el espíritu positivo. Barcelona: Aguilar.

Coronil, F. (2002). El Estado mágico. Naturaleza, dinero y Modernidad en Venezuela. Caracas: Nueva Sociedad.

Dussel, E. (2000). Europa, modernidad y eurocentrismo. En Lander, E. (Ed.), La colonialidad del saber: eurocentrismo y Ciencias Sociales. Perspectivas latinoamericanas (p.p. 41-52). Caracas: Univerisdad Central de Venezuela.

Fabian, J. (1983). Time and the other. How anthropology makes its object. Nueva York: Columbia University Press.

Foucault, M. (1979a). Las palabras y las cosas. México D.F: Siglo XXI.

(1979b). La arqueología del saber. México D.F: Siglo XXI. (1981). La Microfísica del poder. Madrid: La Piqueta.

Geertz, C. (1996). La interpretación de las culturas. Séptima edición en español. Barcelona: Gedisa.

Giddens, A. (1998). La constitución de la sociedad. Bases para la teoría de la estructuración. Buenos Aires: Amorrortu.

Gouldner, A. (1979). La crisis de la sociología occidental. Buenos Aires: Amorrortu.

Gruzinski, S. (1994). La guerra de las imágenes. De Cristóbal 
Colón a Blade Runner. México: Fondo de Cultura Económica.

Hall, S. (2003). Introducción: ¿quién necesita «identidad»? En Hall, S. \& Gay, P. (Comps.), Cuestiones de identidad cultural (pp. 13-39). Buenos Aires: Amorrortu.

Lander, E. (2000a). La colonialidad del saber: eurocentrismo y Ciencias Sociales. Perspectivas latinoamericanas. Caracas: Universidad Central de Venezuela.

(2000b). ¿Conocimiento para qué? ¿Conocimiento para quién? Reflexiones sobre la geopolítica de los saberes hegemónicos, Revista Venezolana de Economía y Ciencias Sociales, 6(2), 53-72.

Lenin, V. [1917] (1975). El Imperialismo, fase superior del Capitalismo. Pekín: Ediciones en lenguas extranjeras.

Lévi-Strauss, C. (1991). Introducción a la obra de Marcel Mauss. En Mauss, M., Sociología y Antropología. Tercera edición en español. Madrid: Tecnos.

Lyotard, J. F. (1987). La condición posmoderna. Madrid: Ediciones Cátedra.

(1999). La posmodernidad (Explicada a los niños). Barcelona: Gedisa.

Marx, K. \& Engels, F. [1859] (1979). La ideología alemana. La Habana.

Mignolo, W. (2000). La colonialidad a lo largo y a lo ancho: el hemisferio occidental en el horizonte colonial de la modernidad". En Lander, E. (Ed.), La colonialidad del saber: eurocentrismo y ciencias sociales. Perspectivas Latinoamericanas (pp. 55-85). Caracas: Universidad Central de Venezuela.

(2001). Capitalismo y geopolítica del conocimiento: el eurocentrismo y la filosofía de la liberación en el debate intelectual contemporáneo. Buenos Aires: Ediciones del Signo.

Pagden, A. (1988). La caída del hombre. El indio americano y los orígenes de la etnología comparativa. Madrid: Alianza Editorial.

Sahlins, M. (1997). Islas de Historia: La muerte del capitán Cook. Metáfora, Antropología e Historia. Tercera edición en español. Barcelona: Gedisa.

Said, E. (1990). Orientalismo. Madrid: Libertarias.

Tiapa, F. (2007a). Los sistemas interétnicos del Oriente de Venezuela y el Bajo Orinoco durante la época colonial (1498-1810). En Meneses, L.; Gordones, G. \& Clarac, J. (Comps.), Lecturas antropológicas de Venezuela (pp. 231-238). Mérida: Universidad de Los Andes.

(2007b). Los conflictos de cacicazgo entre los Chaima de San Félix Cantalicio de Ropopán durante el siglo XVIII. Boletín Antropológico, 6, 83-113.

(2007c). Las relaciones interétnicas entre los Warao de la frontera Noroccidental del Delta del Orinoco durante la época colonial. Trocadero. Revista de Historia Moderna y Contemporánea, 19, 215-228.

(2007d). Los usos políticos del agua en la frontera indígena de Píritu durante la época colonial. Gazeta de Antropología 23, 23 17. http://hdl.handle.net/10481/7044.

(2008a). Resistencia indígena e identidades fronterizas en la colonización del Oriente de Venezuela, siglos XVI-XVIII. Antropológica, 109, 69-112.

(2008b). Teoría antropológica e investigación histórica en el estudio de las sociedades del pasado. Tierra Firme, Revista de Historia y Ciencias Sociales, 101, 91-114.

(2008c). Antropología, historia colonial y descolonización del pasado. Revista Venezolana de Economía y Ciencias Sociales, 4(8), 13-30.

(2010). Ecología histórica de los Kari'ña de los Llanos orientales del río Orinoco durante la época colonial. Antropológica, LIII (113), 77-114.

(2011). Identidad, alteridad y relaciones interétnicas en las fronteras de la Modernidad. Una aproximación desde la teoría antropológica. Fermentum, Revista de Sociología y Antropología, 21(62), 384-414.

(2012). Identidad étnica y patrimonio cultural entre los Kari'ña de la Mesa de Guanipa. Presente y pasado. Revista de Historia, 17(34), 115-132.

(2013). Formulación de un modelo teórico para el análisis de la estructura y transformación histórica del Sistema interétnico del Golfo de Paria durante la época colonial. (Tesis inédita de maestría) Instituto Venezolano de Investigaciones Científicas. Caracas.

(2013b). Los Comuneros de Mérida. Caracas: La Estrella Roja.

(2014a). Del Caribe al Orinoco. Alianzas y redes indígenas como respuesta al Capitalismo Colonial. Caracas: La Estrella Roja. (2014b). Kari'ña, poder popular, industria y autonomía cultural. Del Estado colonizado al Estado por la descolonización. Caracas: La Estrella Roja.

(2015). Racismo, esencialismo y maquinización social: el colonialismo como referente discursivo del Nacionalsocialismo. Fermentum. Revista de Sociología y Antropología, 25(74), 143-153.

(2016). Sistemas interétnicos, matrilocalidad y construcción colonial del patriarcado en el Oriente de Venezuela, siglos XVII y XVIII. Procesos Históricos. Revista de Historia y Ciencias Sociales, 29, 45-76.

Wallerstein, I. (1976). The modern World System I. Capitalist agriculture and the origins of the European World-Economy in the Sixteenth Century. Nueva York: Academic Press.

(2006). Abrir las Ciencias Sociales. Madrid: Siglo XXI.

Weber, M. [1905] (2001). La ética protestante y el espíritu del capitalismo. Madrid: Alianza Editorial.

Wolf, E. (1987). Europa y la gente sin historia. México D.F: Fondo de Cultura Económica. 